African Journal of Microbiology Research Vol. 6(48), pp. 7401-7416, 18 December, 2012

Available online at http://www.academicjournals.org/AJMR

DOI: $10.5897 / A J M R 11.998$

ISSN 1996-0808 @2012 Academic Journals

Full Length Research Paper

\title{
Efficacy of dichlorvos+tetramethrin, Bougainvillea glabra, potassium chloride and Bacillus thuringiensis on Tribolium castaneum
}

\author{
Kausar Malik*, Shaffaf Nizzami, Shagufta Andleeb, Amjad Farooq, Farkhanda Jabeen and \\ Mir Muhammad Ali Talpur
}

Department of the Zoology, Lahore College for Women University, Lahore, Pakistan.

Accepted 19 November, 2012

\begin{abstract}
The present research was based on determining the effect of dichlorvos + tetramethrin $(3.1 \%$ emulsifiable concentrate, EC), Bougainvillea glabra, potassium chloride and Shaf I Bacillus thuringiensis alone or in combination against Tribolium castaneum (Jaculin Du val.) adults and larvae. $B t$ was isolated from samples, cultured on different media by applying microbial techniques and then crystal protein was isolated from bacteria. The bio-toxicity was analyzsed by SPSS software and showed that larvae are more susceptible and showed significant results as compared to adults. Separate bioassays revealed that Shaf I B. thuringiensis was more toxic at all concentrations followed by an insecticide DDVP+tetramethrin, chemical potassium chloride and the least toxic was B. glabra. In the synergistic effect, highest mortality percentage was shown by the bioinsecticide, $B$. thuringiensis. All elements whenever combined together, proved to be useful for the control of stored product pests.
\end{abstract}

Key words: Dichlorvos (2-2, dichlorodivinyl dimethyl phosphate), Bacillus thuringiensis (Bt), EC), Statistical Package of Social Sciences (SPSS), T. castaneum.

\section{INTRODUCTION}

Bacillus thuringiensis crystal proteins are pore-forming toxins used as insecticides around the world also known as a biological pathogen. Crystal toxin proteins from the Gram-positive rod shaped bacterium, $B t$, are used extensively to control insect pests. These range from caterpillars (Lepidoptera) and beetles (Coleoptera) that infest crops to black flies and mosquitoes (Diptera) that transmit human diseases. The red flour beetle (Tribolium castaneum) (Coleopteran: Tenebrionidae) is a common pest of wheat flour and is found worldwide. $B$. thuringiensis has been used in developed countries to control target pest population in medicine, forest areas and agriculture. Many types of standardized formulations

*Corresponding author. E-mail: kausarbasit786@yahoo.com. are available commercially on spore-crystal combinations. The development of formulations with biodegradable property has replaced the use of chemical insecticide which threatens the environment (Garcia and Ninfa, 2009). Tribolium castaneum is commonly known as red flour beetle that attacked the store grain products like nut, beans, meal, flour, pasta, chocolate, spices, cereals, seeds, cake mix and also museum specimens (Via, 1999; Weston and Rattlingourd, 2000). Red flour beetles have mouthparts for chewing but they are not for stinging and biting. These beetles may bring forth allergic responses but do not spread disease (Alanko et al., 2000). The origin of red flour beetle is Indo-Australia and is also found in temperate regions, but will endure the winter in sheltered places where there is essential heat (Tripathi et al., 2001). The larvae and adults of $T$. 
castaneum prey on juvenile stages of rice moth, Corcyra cephalonica. Larvae and adults are big predators of eggs and pupae, so improving adult reproduction or larval development, thereby lessen competition for their descendants (Alabi et al., 2008).

As a model system, $T$. castaneum has been used for the study of environmental relationship, infestation, large brood sizes and short generation time. So, T. castaneum is widely used as an experimental insect in bioassay (Bucher et al., 2005).

A synergistic agent allows the insecticide to be more effective. T. castaneum collected from eight godowns and one silo was tested for their susceptibility to malathion, dichlorvos, fenitrothion, primiphos-methyl and phosphine. All strains were resistant against all the test insecticides in which malathion was more effective then DDVP (Rahman et al., 2007). Comparison was done between natural and five synthetic insecticides belonging to pyrethroids including bioallethrin, tetramethrin, resmethrin, allethrin and bioresmethrin. When all the insecticides were used individually against $T$. castaneum tetramethrin was least effective (Lloyd, 2003). There are currently no published studies in which tetramethrin and DDVP synergized efficacy has been determined for stored pests. Although a lot of studies have been done to determine the synergistic effect between pyrethroid and organophosphate, such combinations has proved to be very effective in controlling red flour beetles (Scott and Snodgrass, 2000).

Leaves of different plants like Azadirachta indica, Ricinus communis, Bougainvillea glabra, Saraca indica and Eucalyptus were evaluated as grain protectants against $T$. castaneum. After 45 days of storage, wheat grains were tested with these leaves powder by using $5 \%$ (by weight) which showed $78-76 \%$ repellency against red flour beetle (Haq et al., 2005). Potassium chloride is a weak chemical and show very low toxicity to adult $T$. castaneum but highly toxic to the larvae. Research was done to examine the pathogenicity of $B t, S$. marscens, by using different chemicals like boric acid, sodium citrate and potassium chloride against termites and Microcerotermes championi. 1\% boric acid and Bt was used against termites and $1 \%$ sodium citrate and potassium chloride with $S$. marscens was used against M. championi. Virulence was increased ranging from 1.51.8 for Bt and 1.3-1.6 for S.marscens. Boric acid is quite toxic to termites but sodium citrate and potassium chloride were nontoxic to M. championi (Khan, 2006).

The present research was based on the combination effect of Bacillus thuringiensis, chemical (potassium chloride), plant powder (Bougainvillea glabra) and insecticide (DDVP and Tetramethrin) to check their synergistic effects against Tribolium castaneum.

\section{MATERIALS AND METHODS}

\section{Rearing of $T$. castaneum}

For bioassay, adults and third instar larvae were collected in large amount. For rearing, about 100-200 adults of red flour beetle were added in glass jars. The jars were kept in the Zoology Research Laboratory of Lahore College for Women University, in an incubator at $37^{\circ} \mathrm{C}$, with relative humidity of $75 \%$ for feeding and oviposition.

\section{Collection of Bacillus thuringiensis samples}

300 samples were collected from different areas of Lahore including bird droppings, soil and grain dust. Samples were placed in glass jars properly labeled. The jars were brought to the Zoology Research Laboratory of LCWU and placed in refrigerator at $4^{\circ} \mathrm{C}$.

\section{Isolation of $B$. thuringiensis from samples}

For the isolation of $B$. thuringiensis, Lauria Broth medium was prepared by adding $10 \mathrm{~g}$ Tryptone, $5 \mathrm{~g}$ yeast extract, $5 \mathrm{~g} \mathrm{NaCl}$ and $0.2 \mathrm{M}$ sodium acetate in $1 \mathrm{~L}$ of distilled water. Subsequently, $10 \mathrm{ml}$ of LB medium was taken in a beaker and $0.5 \mathrm{~g}$ of soil sample was added in the beaker. It was well shaken and placed in an incubator at $30^{\circ} \mathrm{C}$ for $4 \mathrm{~h}$. After time completion, samples were filtered and heated at $80^{\circ} \mathrm{C}$ for $15 \mathrm{~min}$. Then, samples were diluted and spread on LB agar plates by using spreader. Plates were incubated for overnight at $30^{\circ} \mathrm{C}$. Colonies with $B$. thuringiensis like characteristics and morphology were picked and streaked on LB agar medium.

\section{Microbial screening of $B$. thuringiensis samples}

Shaf I B. thuringiensis cells were grown on Petri plates of T3 medium and it contained $2 \mathrm{~g}$ Tryptose, $3 \mathrm{~g}$ Tryptone, $1.5 \mathrm{~g}$ yeast extract, $0.005 \mathrm{~g}$ of $\mathrm{MnCl}_{2} .2 \mathrm{H}_{2} \mathrm{O}, 2.5 \mathrm{ml}$ of $1 \mathrm{M}$ potassium phosphate (pH 6.9) and lastly $15 \mathrm{~g}$ of agar was added. After that, the mouth of conical flask was covered with cotton plug and aluminum foil and it was then autoclaved. T3 media was poured in plates by filling them less than half. All poured plates were placed in an incubator for 24 $\mathrm{h}$ at $37^{\circ} \mathrm{C}$. After that, Shaf I B. thuringiensis was streaked on the T3 media from the samples, labeled and then placed in an incubator for $72 \mathrm{~h}$ at $37^{\circ} \mathrm{C}$. For bioassay, the growth of Shaf I Bt from T3 media was collected in falcon tubes filled with autoclaved distilled water and was placed in refrigerator at $4^{\circ} \mathrm{C}$.

\section{Biochemical characterization of Shaf I B. thuringiensis}

A single colony of $B t$ was subjected to gram staining, endospore staining and tests for further identification.

In Gram staining method, Bt cells were taken on a sterilized slide with a drop of water, and smear was fixed by flame. Smeared portion was flooded with Crystal violet stain after $15 \mathrm{~s}$, and rinsed with water. lodine stain was applied on smear and after $15 \mathrm{~s}$, rinsed with water and after that, ethyl alcohol was applied evenly on the entire smear for decolourization, and quickly rinse with water. Finally, counter stain Safranin was applied on the smear after $15 \mathrm{~s}$; smear was rinsed with water, was air dried and was observed under Camera Fitter Microscope. In endospore staining, Bt cells were taken on a sterilized slide with a drop of water and thin smear was 
formed, and was fixed with flame. Patch of filter paper was put on the smear, then slide was placed on boiling water beaker and flooded with Malachite green stain at filter paper patch for 20 min. After that, stain was washed with water. Finally, counter stain Safranin was added on the smear, slide was air dried and observed under Camera Fitter microscope.

In this biochemical test, $7 \%(\mathrm{w} / \mathrm{v})$ trypticase salt was used. LB broth medium in the test tubes were inoculated with Shaf I Bt strain. Shaf I Bt cells were streaked evenly across a potato starch plate and incubated at $30^{\circ} \mathrm{C}$ for $96 \mathrm{~h}$. Afterward, plate was stained with iodine solution.

\section{Bioassay}

Estimated value of $\mathrm{LC}_{50}$ used mostly in Bioassay is analyzed through probit from SPSS.

\section{Bioassay of Bougainvillea glabra}

B. glabra was collected from Bagh-e-Jinnah. Leaves were separated from the branches of the plant body and then air dried at room temperature for 7 to 14 days. Dried leaves were ground in electric grinder. After achieving fine plant powder, different concentrations were $(1.5,2.0,2.5 \mathrm{~g}$ and Control) combined with 1 $\mathrm{g}$ diet containing semolina and yeast extract. $B$. glabra bioassays set was run in triplicate by introducing 20 adults in each vial, similarly 2nd instar larvae were introduced in each vial and repeated in triplicate with $1 \mathrm{~g}$ diet to determine mortality rate and $\mathrm{LC}_{50}$ values up to 3 days.

\section{Bioassay of potassium chloride}

Potassium chloride was used in the evaluation of bioassays in three different concentrations (1.5, 2.0, $2.5 \mathrm{~g}$ and control). Bioassay set was run in triplicate by introducing 20 adults in each vial with $1 \mathrm{~g}$ diet consisting of semolina and yeast extract. Similarly, 2nd instars larvae were introduced in each vial and repeated in triplicate with 1 $g$ diet to observe mortality rate and $\mathrm{LC}_{50}$ values up to 3 days.

\section{Bioassay of Tetramethrin+Dichlorvos}

Three different concentrations were used $(0.05,0.15,0.25 \%$ and control without insecticides but with acetone) against $T$. castaneum adults and larvae. Tetramethrin+DDVP were diluted in $10 \mathrm{ml}$ acetone. From the stock solution of each concentration of insecticide \% age was converted into $\mathrm{ug} / \mathrm{ml}$ and very small quantity was used against adult and larvae. Insecticide when added into the vial was vaporized for few minutes due to their volatile nature so that insecticide runs all over the walls of vials. Bioassay set was run in triplicate by introducing 20 adults in each vial with $1 \mathrm{~g}$ diet consisting of semolina and yeast extract; similarly 2 nd instars larvae were introduced in each vial and repeated in triplicate with $1 \mathrm{~g}$ diet to observe Mortality rate and $\mathrm{LC}_{50}$ values up to 3 days.

\section{Bioassay of Shaf I Bacillus thuringiensis}

Shaf I Bt grown cultures from Petri plates were scraped and washed three times with distilled water and centrifuged at 3000 rpm. Shaf I Bt pellet was obtained, and collected growth of pure culture was centrifuged three times. After that, Bt was mixed in $1 \mathrm{~g}$ diet of semolina and yeast extract, dried and then ground with pestle and mortar. Different concentrations were used (1.0, 1.5, 2.0 $\mathrm{g}$ and control without $B t$ but with agar). Bioassay set was run in triplicate by introducing 20 adults in each vial with $1 \mathrm{~g}$ diet consisting of semolina and yeast extract, and similarly 2nd instars larvae were introduced in each vial and repeated in triplicate with 1 $g$ diet to observe mortality rate and $L_{50}$ values up to 3 days.

\section{Combined bioassay}

In the combined bioassay, all the elements were mixed together and three different concentrations were formed and bioassay was done against adult $T$. castaneum and third instar larvae separately; first combination (1.5 g B. glabra powder, $1.5 \mathrm{~g} \mathrm{KCl}, 0.05 \%$ Tetramethrin+DDVP and $1 \mathrm{~g}$ Shaf I Bt) second combination $(2.0 \mathrm{~g}$ B. glabra powder, $2.0 \mathrm{~g} \mathrm{KCl}, 0.15 \%$ Tetramethrin+DDVP and $1.5 \mathrm{~g}$ Shaf I Bt) and third combination $(2.5 \mathrm{~g} \mathrm{B.glabra} \mathrm{powder,} 2.5 \mathrm{~g} \mathrm{KCl}$, $0.25 \%$ Tetramethrin+DDVP and $2.0 \mathrm{~g}$ Shaf I $\mathrm{Bt}$ ). Bioassay set was run in triplicate by introducing 20 adults in each vial with $1 \mathrm{~g}$ diet consisting of semolina and yeast extract. Similarly, 20 larvae were introduced in each vial and repeated in triplicate with $1 \mathrm{~g}$ diet to observe percentage mortality for 3 days separately and in combination.

\section{Analysis of data}

Results of bioassays were analyzed by using probit on SPSS 17.0 software. Lethal concentration $\left(\mathrm{LC}_{50}\right)$ values were observed at each day and of all three concentrations.

\section{RESULTS}

\section{Collection of $B$. thuringiensis from samples}

Of 300 samples collected, B. thuringiensis was isolated from bird droppings, grain dust and soil from various localities. Strain Shaf I was found in large amount.

\section{Morphological and biochemical characterization of Shaf I B. thuringiensis}

By growing on LB medium turbidity confirms the status of $B t$. When Bt was streaked on T3 medium, it showed characteristic morphology. Grown colonies were white in color, sometimes dry, opaque, slippery, mucoid and smooth colonies (Figure 3).

After Gram and Endospore staining, the spores appeared green and produced central or ellipsoidal parasporal crystals and pink vegetative cells thus retained the purple color of crystal violet, confirming their status as Gram-positive rods in chains and single form (Figures 1 and 2, Table 1). In the 7\% sodium chloride test, turbidity was observed after 14 days of incubation at 


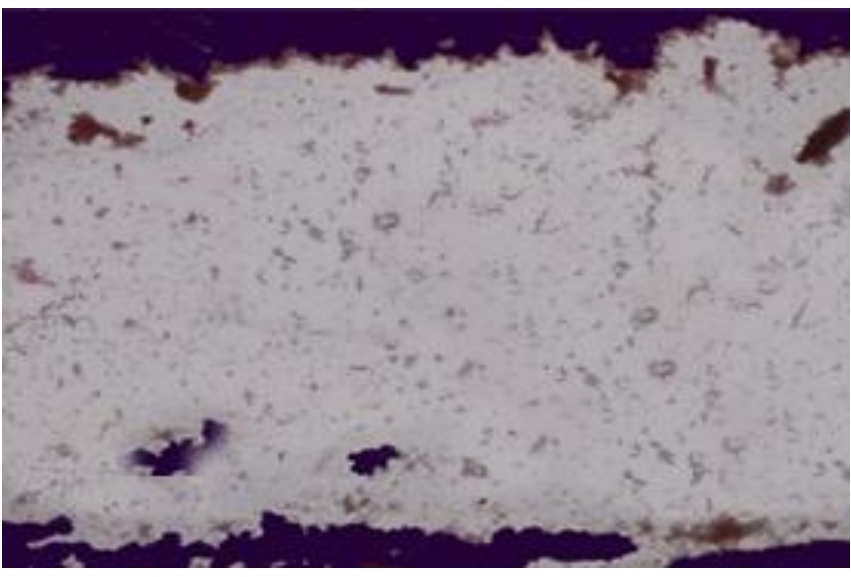

Figure 1. Gram staining results of rod shaped and Gram positive shaf I Bacillus thuringiensis.

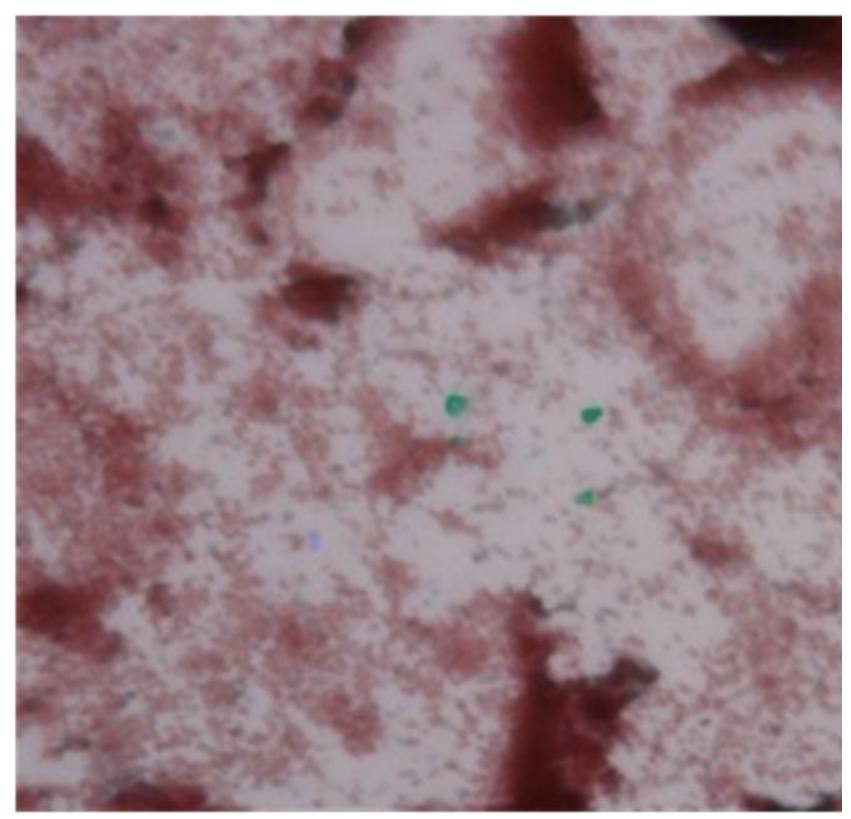

Figure 2. Endospore staining results of Shaf I Bacillus thuringiensis.

$37^{\circ} \mathrm{C}$. In starch hydrolysis test, starch appeared blue black and clear zone was indicated after hydrolysis.

\section{Bioassay of adults}

Bioassay or biological standardization is such type of scientific experiments which are used to measure the effect of a substance on test organism. T. castaneum is a

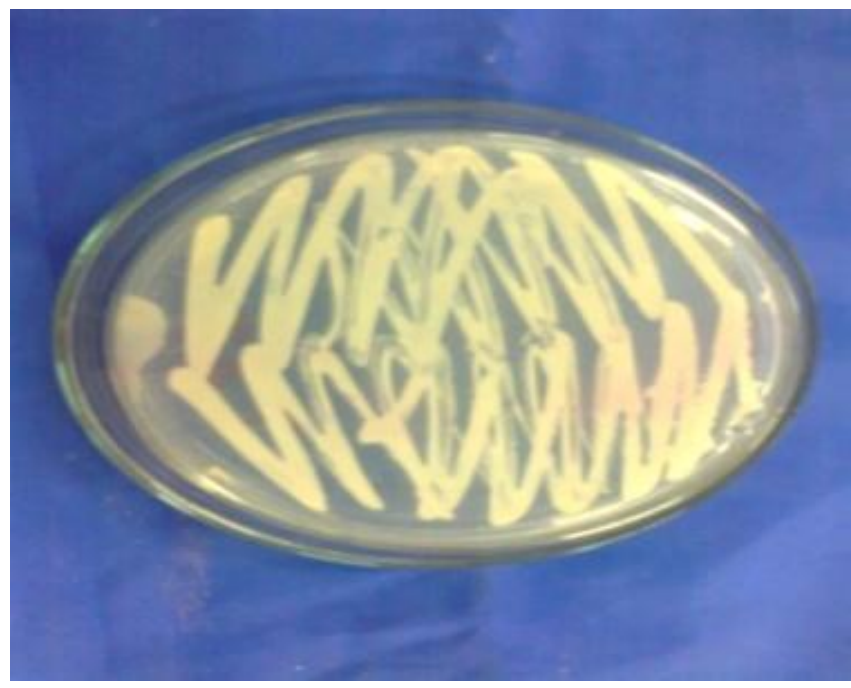

Figure 3. Petri plates are showing Streaking results of Shaf I Bacillus thuringiensis colonies grown on T3 medium.

model organism for bioassay methods. Adults of $T$. castaneum have a characteristic potential to show its efficacy against different concentrations of Shaf $I B$. thuringiensis, B. glabra, potassium chloride, Tetramethrin and DDVP separately and in combination. At different concentrations, adults showed different mortality percentage, with regression equal or near to 1 after 3 days observations (Figures 4 to 6 ). By using probit in SPSS 17.0, $\mathrm{LC}_{50}$ was counted according to days of the three concentrations.

\section{Bioassay of Shaf I B. thuringiensis}

The purpose of using bioassays based on an artificial diet is to provide worker, a rapid and standardized procedure for estimating activity of a microbial strain. At $1 \mathrm{~g}$ B.thuringiensis, 35\% mortality was observed after 3 days. Similarly at $1.5 \mathrm{~g} \mathrm{~B}$. thuringiensis, $41.6 \%$ and at $2.0 \mathrm{~g} \mathrm{~B}$. thuringiensis $50 \%$ mortality was observed (Table 2). Regression line was equal or near to 1 (Figures 7 and 8). LC50 was determined by probit analysis according to days in which at $24 \mathrm{~h}$ of all three concentrations, LC50 value was $8.7 \mathrm{~g} / \mathrm{g}$ artificial diet. However, at $48 \mathrm{~h}$ and 72 $\mathrm{h}, \mathrm{LC}_{50}$ values were $6.2 \mathrm{~g} / \mathrm{g}$ and $8.2 \mathrm{~g} / \mathrm{g}$ respectively (Table 3).

\section{Bioassay of potassium chloride}

At $1.5 \mathrm{~g}$ concentration, $25 \%$, at $2.0 \mathrm{~g} 28.3 \%$ and at $2.5 \mathrm{~g}$ $38.3 \%$ mortality was observed after 3 days (Table 4 ). 
Table 1. Gram staining and endospore staining Shaf I of Bacillus thuringiensis.

\begin{tabular}{|c|c|c|c|c|c|}
\hline \multirow{2}{*}{ Serial number } & \multirow{2}{*}{ Isolate } & \multirow{2}{*}{ Gram staining } & \multirow{2}{*}{ Cell arrangement } & \multicolumn{2}{|c|}{ Endospore staining } \\
\hline & & & & Spore & Vegetative cell \\
\hline 1 & Shaf I & Gram positive & Single and Chains & Green & Pink \\
\hline
\end{tabular}

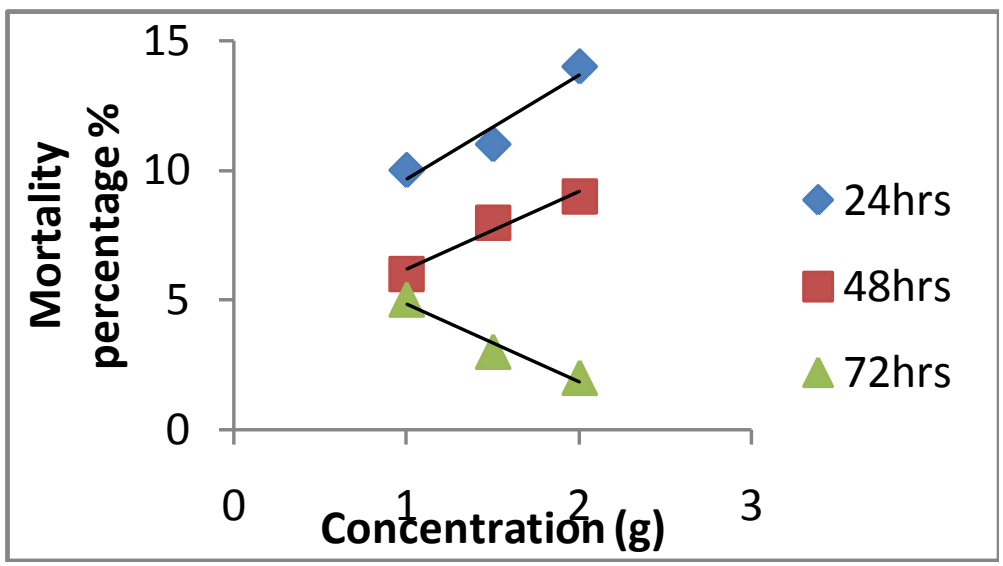

Figure 4. Regression lines of mortality percentage versus different concentration of Shaf $I B$. thuringiensis against adults of $T$. castaneum at different time interval.

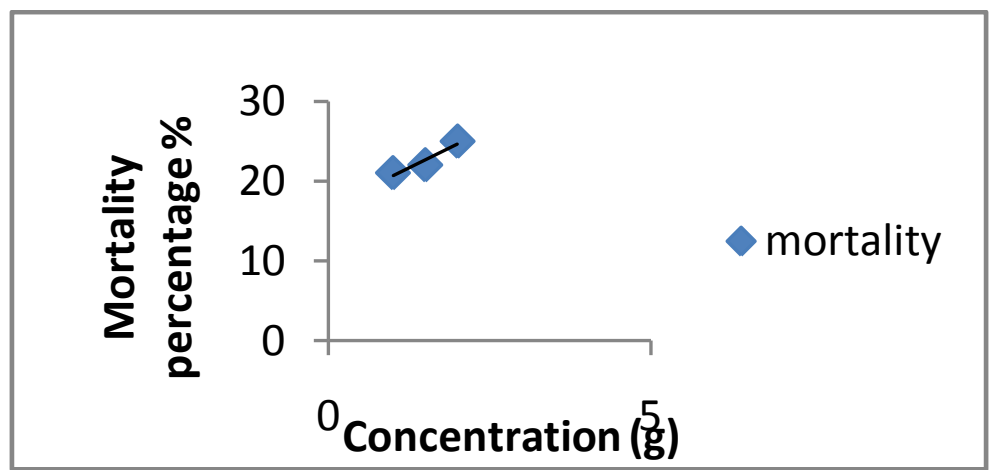

Figure 5. Regression lines of total mortality percentage versus different concentration of Shaf I B. thuringiensis against adults of $T$. castaneum.

Regression line was equal or near to 1 (Figures 9 and 10). $\mathrm{LC}_{50}$ value of the three concentrations at $24 \mathrm{~h}$ was $5.5 \mathrm{~g} / \mathrm{g}$ artificial diet, at $48 \mathrm{~h} 6.0 \mathrm{~g} / \mathrm{g}$ and at $72 \mathrm{~h} 10.9 \mathrm{~g} / \mathrm{g}$ (Table 5).

\section{Bioassay of Bougainvillea glabra}

At all concentrations, no mortality was observed. B. glabra enhanced the developmental period of adults $T$. castaneum. No statistics was applied for $\mathrm{LC}_{50}$.

\section{Bioassay of tetramethrin and DDVP}

Synergistic effect of Tetramethrin and DDVP shows high magnitude against T.castaneum adults. At $0.05 \mathrm{~g}$ mortality was $45 \%$, at $0.15 \mathrm{~g} 51.6 \%$ and at $0.25 \mathrm{~g} 58.3 \%$ mortality was observed (Table 6). Regression line was 


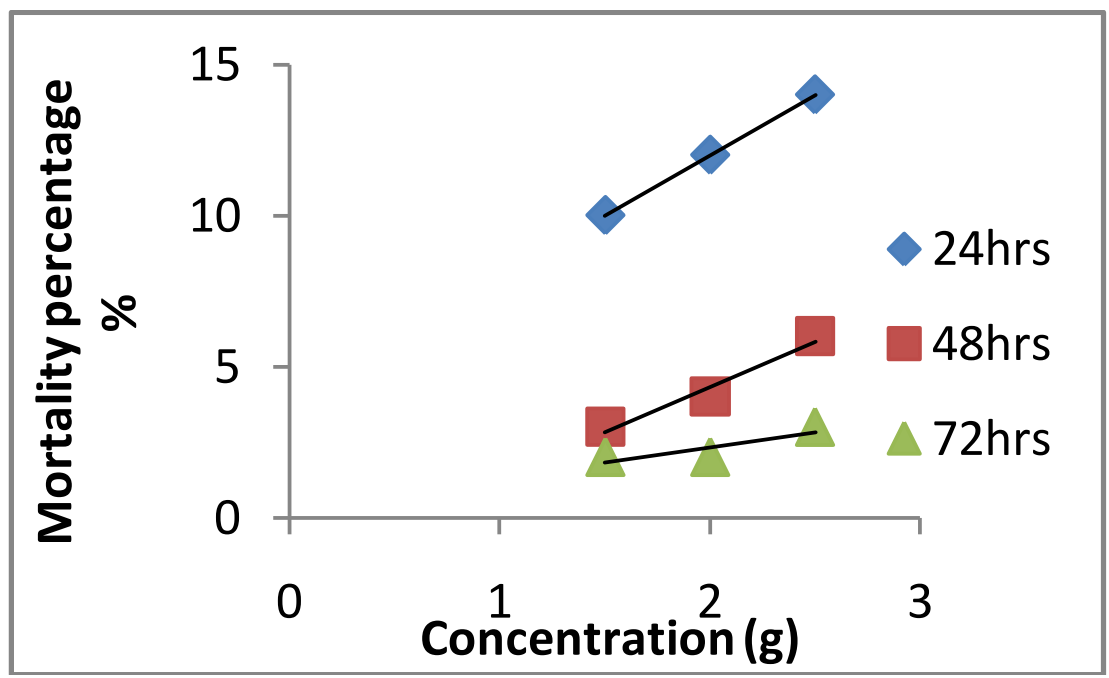

Figure 6. Regression lines of mortality percentage versus different concentration of potassium chloride against adults of $T$. castaneum at different time interval.

Table 2. Bioassay results of Shaf I $B$. thuringiensis at different concentrations showing percent mortality.

\begin{tabular}{|c|c|c|c|c|c|c|c|}
\hline \multirow{2}{*}{$\begin{array}{c}\text { Serial } \\
\text { number }\end{array}$} & \multirow{2}{*}{$\begin{array}{c}\text { Concentration } \\
\text { (g) }\end{array}$} & \multirow{2}{*}{$\begin{array}{l}\text { Number of } \\
\text { used adult }\end{array}$} & \multicolumn{3}{|c|}{ Time (h) } & \multirow{2}{*}{$\begin{array}{c}\text { Percentage } \\
\text { mortality (\%) }\end{array}$} & \multirow{2}{*}{$\mathbf{R}^{2}$ of all concentration } \\
\hline & & & 24 & 48 & 72 & & \\
\hline 1 & 1.0 & 60 & 10 & 6 & 5 & 35 & \multirow{4}{*}{0.9} \\
\hline 2 & 1.5 & 60 & 11 & 8 & 6 & 41.6 & \\
\hline 3 & 2.0 & 60 & 14 & 9 & 7 & 50 & \\
\hline 4 & Control & 60 & 0 & 0 & 0 & 0 & \\
\hline
\end{tabular}

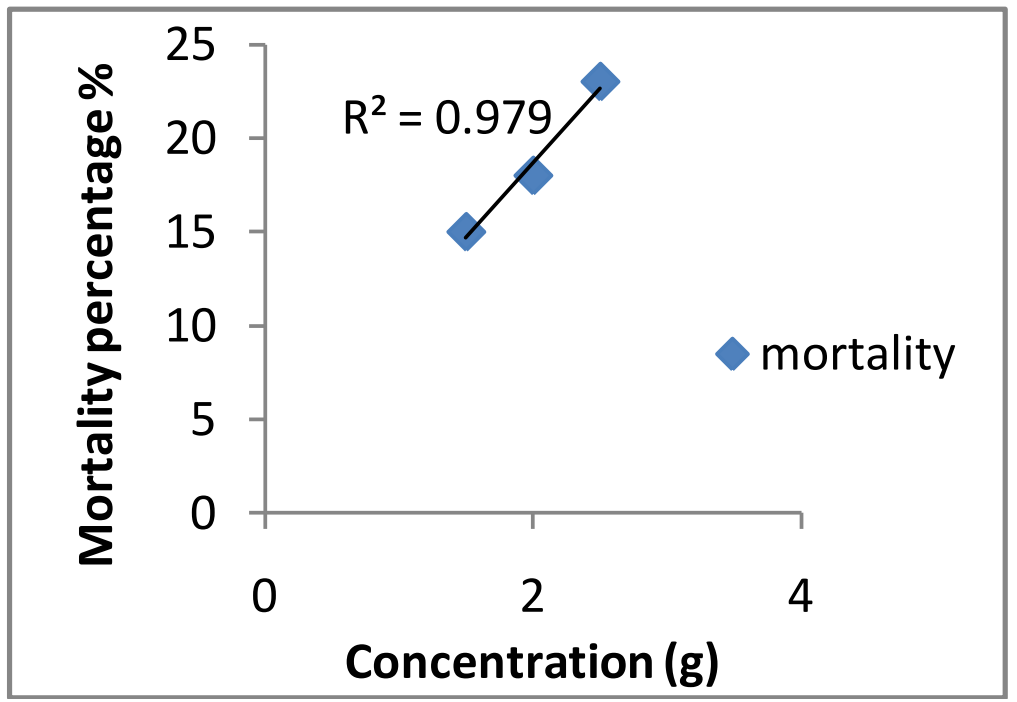

Figure 7. Regression lines of total mortality percentage versus 3 concentration of potassium chloride against adults of $T$. castaneum. 


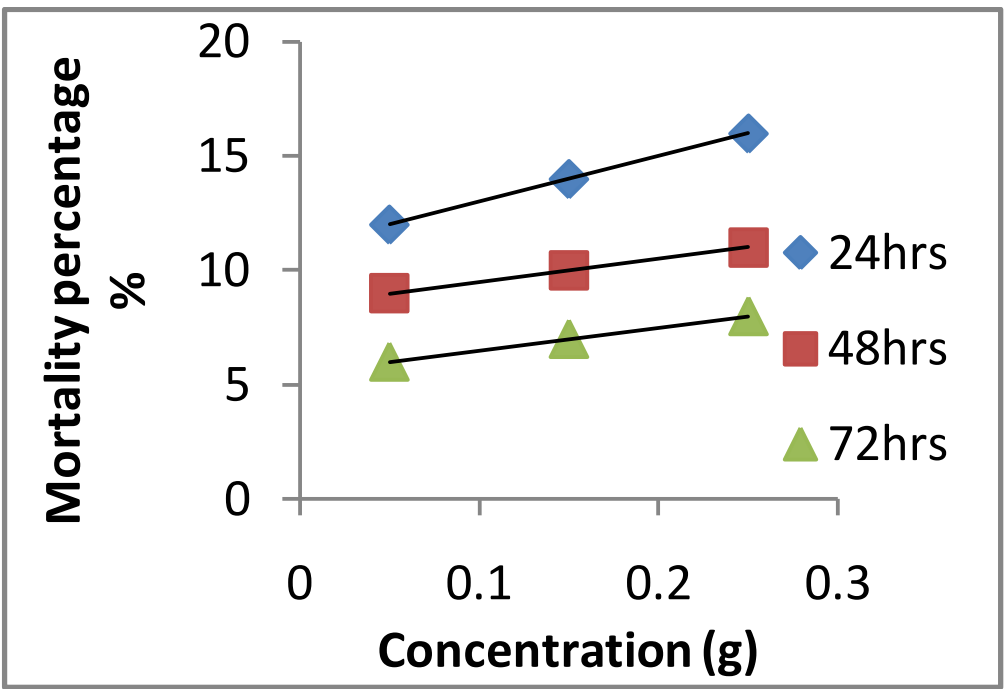

Figure 8. Regression lines of mortality percentage versus different concentration of Tetramethrin and DDVP against adults of $T$. castaneum at different time interval.

Table 3. Toxicity of Shaf I B. thuringiensis against Tribolium castaneum showing LC $_{50}$ value.

\begin{tabular}{ccccccc}
\hline \multirow{2}{*}{ Serial number } & \multirow{2}{*}{ Time (h) } & \multicolumn{3}{c}{ Concentration $\mathbf{( g )}$} & \multirow{2}{*}{ CC $_{50}(\mathbf{g} / \mathbf{g})$} & \multirow{2}{*}{$\begin{array}{c}\text { LC }_{50} \text { value of all three } \\
\text { concentration }(\mathbf{g} / \mathbf{g})\end{array}$} \\
\cline { 3 - 5 } & & $\mathbf{1 . 0}$ & $\mathbf{1 . 5}$ & $\mathbf{2 . 0}$ & & \\
2 & 24 & 10 & 11 & 14 & 8.7 & 2.1 \\
3 & 48 & 6 & 8 & 9 & 6.2 & \\
\hline
\end{tabular}

Table 4. Bioassay results of Potassium chloride at different concentrations showing percent mortality.

\begin{tabular}{|c|c|c|c|c|c|c|c|}
\hline \multirow{2}{*}{$\begin{array}{c}\text { Serial } \\
\text { number }\end{array}$} & \multirow{2}{*}{$\begin{array}{c}\text { Concentration } \\
\text { (g) }\end{array}$} & \multirow{2}{*}{$\begin{array}{l}\text { Number of } \\
\text { used adult }\end{array}$} & \multicolumn{3}{|c|}{ Time (h) } & \multirow{2}{*}{$\begin{array}{c}\text { Percentage (\%) } \\
\text { mortality }\end{array}$} & \multirow{2}{*}{$\mathbf{R}^{2}$ of al concentration } \\
\hline & & & 24 & 48 & 72 & & \\
\hline 1 & 1.5 & 60 & 10 & 3 & 2 & 25 & \multirow{4}{*}{0.9} \\
\hline 2 & 2.0 & 60 & 12 & 4 & 1 & 28.3 & \\
\hline 3 & 2.5 & 60 & 15 & 5 & 3 & 38.3 & \\
\hline 4 & Control & 60 & 0 & 0 & 0 & 0 & \\
\hline
\end{tabular}

equal or near to 1 (Figure 11 and 12). LC $_{50}$ was counted for 3 days separately, at $24 \mathrm{~h}, \mathrm{LC}_{50}$ of three concentrations was 0.8 . Similarly, at $48 \mathrm{~h}$ and $72 \mathrm{~h}, \mathrm{LC}_{50}$ was 1.6 and 1.5 (Table 7).

\section{Combine bioassay}

In the combine bioassay, all the elements were mixed together and three different concentrations were formed and bioassay was done against adult T.castaneum.
Percentage mortality was different for the three concentrations and mortality increased at higher concentration (Table 8).

\section{Bioassay of larvae}

Larvae of $T$. castaneum had a characteristic potential and showed its efficacy against different concentrations of $B$. thuringiensis, B. glabra, potassium chloride, Tetramethrin and DDVP separately and in combination. 


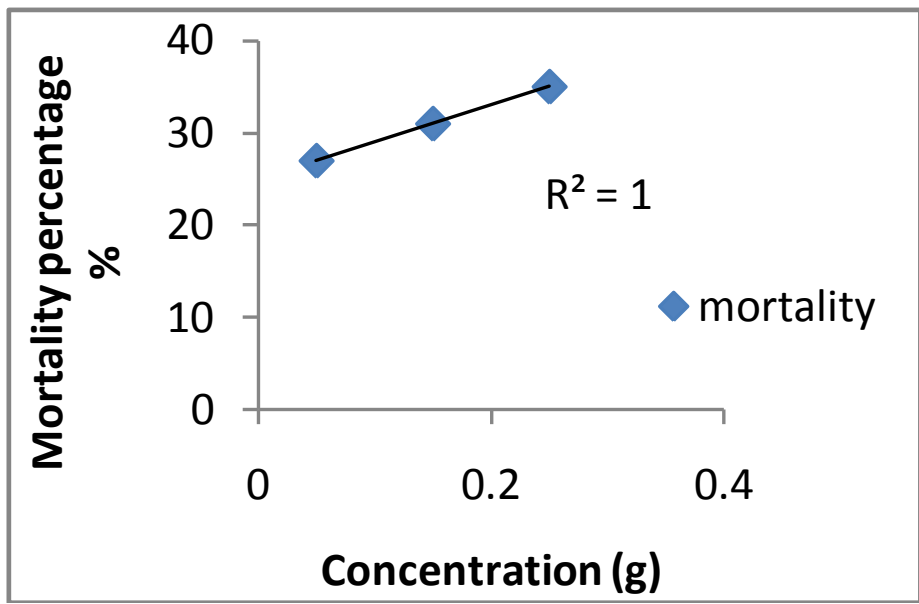

Figure 9. Regression lines of total mortality percentage versus 3 concentrations of Tetramethrin and DDVP against adults of $T$. castaneum.

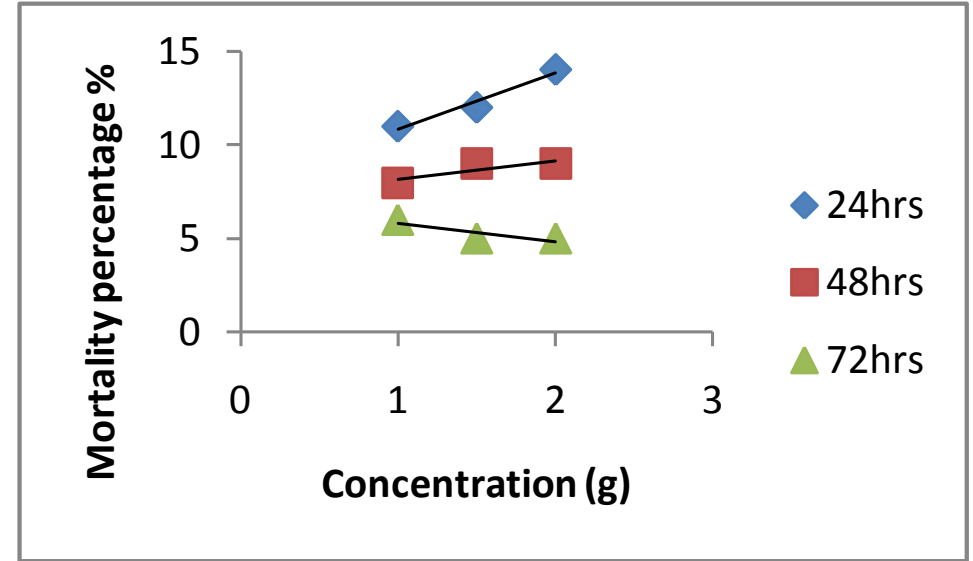

Figure 10. Regression lines of mortality percentage versus different concentration of Shaf I B. thuringiensis against third instar larvae of Tribolium castaneum at different time interval.

Table 5. Toxicity of potassium chloride against $T$. castaneum showing $L C_{50}$ value.

\begin{tabular}{|c|c|c|c|c|c|c|}
\hline \multirow{2}{*}{ Serial number } & \multirow{2}{*}{ Time (h) } & \multicolumn{2}{|c|}{ Concentratior } & \multirow{2}{*}{ (g) } & \multirow{2}{*}{$\mathrm{LC}_{50}(\mathrm{~g} / \mathrm{g})$} & \multirow{2}{*}{$\begin{array}{c}\mathrm{LC}_{50} \text { value of all } 3 \\
\text { concentrations }(\mathrm{g} / \mathrm{g})\end{array}$} \\
\hline & & 1.5 & 2.0 & & & \\
\hline 1 & 24 & 10 & 12 & 14 & 5.5 & \\
\hline 2 & 48 & 3 & 4 & 6 & 6.0 & 3.3 \\
\hline 3 & 72 & 2 & 2 & 3 & 10.9 & \\
\hline
\end{tabular}

\section{Bioassay of Shaf I B. thuringiensis}

At $1 \mathrm{~g} \mathrm{Bt}, 40 \%$ mortality was observed after 3 days.
Similarly at $1.5 \mathrm{~g} \mathrm{Bt}, 45 \%$ and at $2.0 \mathrm{~g} \mathrm{Bt} 51.6 \%$ mortality was observed. (Table 9). Regression line was equal or near to 1 (Figures 13 and 14). LC 50 was determined by 
Table 6. Bioassay results of Tetramethrin+DDVP at different concentrations showing percent mortality.

\begin{tabular}{cccccccc}
\hline \multirow{2}{*}{$\begin{array}{c}\text { Serial } \\
\text { number }\end{array}$} & $\begin{array}{c}\text { Concentration } \\
(\%)\end{array}$ & $\begin{array}{c}\text { Number used } \\
\text { adult }\end{array}$ & \multicolumn{3}{c}{ Time (h) } & Percentage & \multirow{2}{*}{$\mathbf{R}^{2}$ of all three concentration } \\
\cline { 5 - 6 } mortality (\%) & $\mathbf{2 4}$ & $\mathbf{4 8}$ & $\mathbf{7 2}$ & \\
\hline 1 & 0.05 & 60 & 12 & 9 & 6 & 45 & \\
2 & 0.15 & 60 & 14 & 10 & 7 & 51.6 & 1 \\
3 & 0.25 & 60 & 16 & 11 & 8 & 58.3 & \\
4 & Control & 60 & 0 & 0 & 0 & 0 & \\
\hline
\end{tabular}

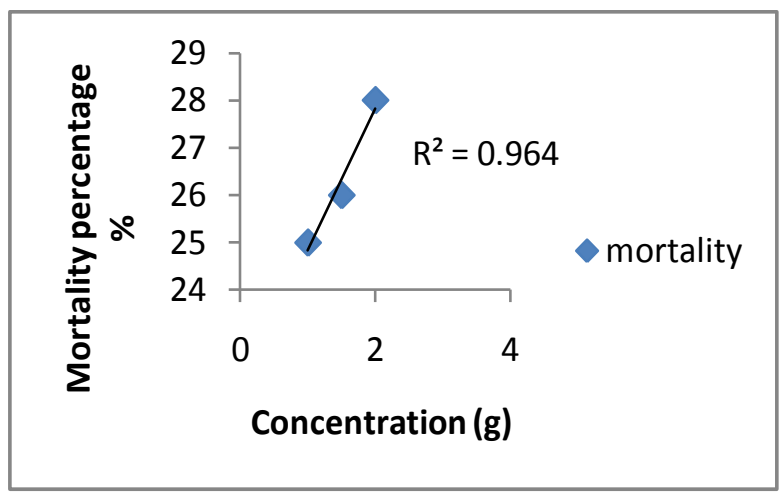

Figure 11. Regression lines of mortality percentage versus different concentration of Shaf $I B$. thuringiensis against third instar larvae of Tribolium castaneum at different time interval.

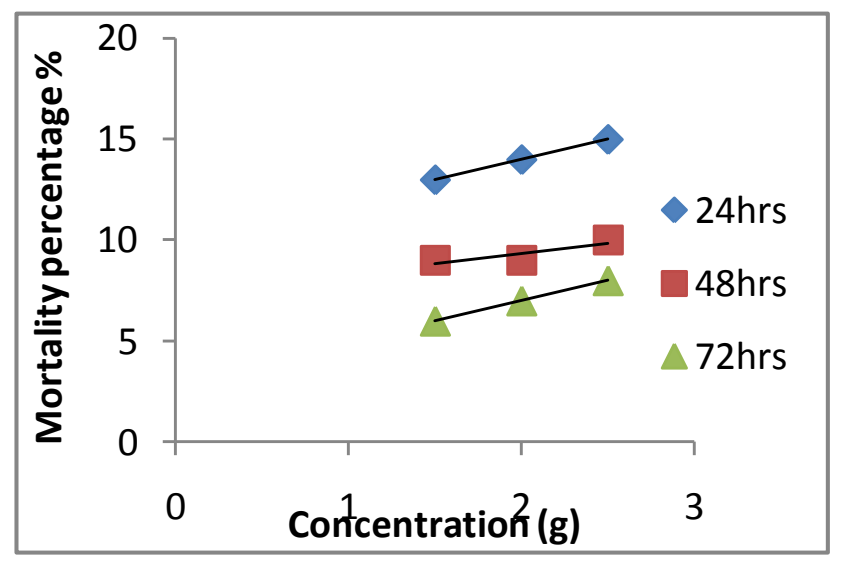

Figure 12. Regression lines of mortality percentage versus different concentration of Potassium Chloride against third instar larvae of Tribolium castaneum at different time interval.

probit analysis according to days in which at $24 \mathrm{~h}$ of all three concentrations $\mathrm{LC}_{50}$ value was $6.2 \mathrm{~g} / \mathrm{g}$. However, at 48 and $72 \mathrm{~h}, \mathrm{LC}_{50}$ value was 8.7 and $8.2 \mathrm{~g} / \mathrm{g}$ (Table 10).

\section{Bioassay of potassium chloride}

At $1.5 \mathrm{~g}, 45 \%$, at $2.0 \mathrm{~g} 50 \%$ and at $2.5 \mathrm{~g} 55 \%$ mortality was observed after 3 days (Table 11). Regression line was equal or near to 1 (Figures 15 and 16). LC 50 value of the three concentrations at $24 \mathrm{~h}$ was $8.7 \mathrm{~g} / \mathrm{g}$ at $48 \mathrm{~h}$, the value was $9.2 \mathrm{~g} / \mathrm{g}$ and at $72 \mathrm{~h}$ it was $9.0 \mathrm{~g} / \mathrm{g}$ (Table 12)

\section{Bioassay of Bougainvillea glabra}

At all concentrations, no mortality was observed. No statistics was applied for $\mathrm{LC}_{50}$.

\section{Bioassay of Tetramethrin and DDVP}

At $0.05 \mathrm{~g}$ mortality observed was $50 \%$, at $0.15 \mathrm{~g} 56.6 \%$ and at $0.25 \mathrm{~g}$ it was $63.3 \%$. (Table 13) Regression line was equal or near to 1 (Figures 17 and 18). LC 50 was counted for 3 days separately, at $24 \mathrm{~h}$. LC $_{50}$ of the three concentrations was $0.6 \%$. Similarly, at $0.15 \mathrm{~g}$, it was $1.6 \%$ and at $0.25 \mathrm{~g}, 1.5 \% \mathrm{LC}_{50}$ was counted (Table 14 ).

\section{Combine bioassay}

In the combine bioassay, three different concentrations were formed and bioassay was done against third instar larvae of $T$. castaneum. Percentage mortality was different for the three concentrations and mortality increased at higher concentration (Table 15).

\section{DISCUSSION}

In this study, $B$. thuringiensis acted as biological insecticide and showed low mortality at lower concentration and high mortality at higher concentration. Regression was equal or near 1 . The adult $\mathrm{LC}_{50}$ value for all three concentrations was about $2.1 \mathrm{~g} / \mathrm{g}$ while larvae showed $1.8 \mathrm{~g} / \mathrm{g}$ value of $\mathrm{LC}_{50}$. In both cases, by increasing the concentration, more number of insects 
Table 7. Toxicity of Tetramethrin+DDVP against $T$. castaneum showing $\mathrm{LC}_{50}$ value.

\begin{tabular}{|c|c|c|c|c|c|c|}
\hline \multirow{2}{*}{$\begin{array}{l}\text { Serial } \\
\text { number }\end{array}$} & \multirow{2}{*}{ Time (h) } & \multicolumn{2}{|c|}{ Concentration } & (g) & \multirow{2}{*}{$\mathbf{L C}_{50}(\%)$} & \multirow{2}{*}{$\begin{array}{l}\mathrm{LC}_{50} \text { value of all three } \\
\text { concentration (\%) }\end{array}$} \\
\hline & & 0.05 & 0.15 & 0.25 & & \\
\hline 1 & 24 & 12 & 14 & 16 & 0.8 & \\
\hline 2 & 48 & 9 & 10 & 11 & 1.6 & 1.6 \\
\hline 3 & 72 & 6 & 7 & 8 & 1.5 & \\
\hline
\end{tabular}

Table 8. Comparison of individual and combine effect of Shaf I Bacillus thuringiensis, Potassium chloride, Bougainvillea glabra and Tetramethrin+DDVP on T. castaneum larvae at 24,48 and $72 \mathrm{~h}$.

\begin{tabular}{|c|c|c|c|c|}
\hline $\begin{array}{c}\text { Time } \\
\text { interval (h) }\end{array}$ & Concentration & $\begin{array}{l}\text { Combine and individual } \\
\text { concentration mixed with diet }\end{array}$ & $\begin{array}{c}\text { Observed mortality } \\
(\mathrm{D} / \mathrm{T})\end{array}$ & $\begin{array}{c}\text { Percentage } \\
\text { mortality (\%) }\end{array}$ \\
\hline \multirow[t]{6}{*}{24} & First concentration & Control & $0 / 60$ & 0 \\
\hline & & $\mathrm{KCL}(1.5 \mathrm{~g})$ & $10 / 60$ & 16.6 \\
\hline & & B.t $(1.0 \mathrm{~g})$ & $10 / 60$ & 16.6 \\
\hline & & B. glabra $(1.5 \mathrm{~g})$ & $0 / 60$ & 0 \\
\hline & & Tet+DDVP $(0.05 \%)$ & $12 / 60$ & 20 \\
\hline & & Combine & $32 / 60$ & 53.3 \\
\hline \multirow[t]{6}{*}{48} & & Control & $0 / 60$ & 0 \\
\hline & & $\mathrm{KCL}$ & $3 / 60$ & 5 \\
\hline & & B.t & $6 / 60$ & 10 \\
\hline & & B. glabra & $0 / 60$ & 0 \\
\hline & & Tet+DDVP & $9 / 60$ & 15 \\
\hline & & Combine & $18 / 60$ & 30 \\
\hline \multirow[t]{6}{*}{72} & & Control & $0 / 60$ & 0 \\
\hline & & $\mathrm{KCL}$ & $2 / 60$ & 3.3 \\
\hline & & B.t & $5 / 60$ & 1.6 \\
\hline & & B. glabra & $0 / 60$ & 0 \\
\hline & & Tet+DDVP & $6 / 60$ & 13.3 \\
\hline & & Combine & $13 / 60$ & 21.6 \\
\hline \multirow[t]{6}{*}{24} & Second concentration & Control & $0 / 60$ & 0 \\
\hline & & $\mathrm{KCL}(2.0 \mathrm{~g})$ & $12 / 60$ & 20 \\
\hline & & B.t $(1.5 \mathrm{~g})$ & $11 / 60$ & 18.3 \\
\hline & & B. glabra $(2.0 \mathrm{~g})$ & $0 / 60$ & 0 \\
\hline & & Tet+DDVP $(0.15 \%)$ & $14 / 60$ & 23.3 \\
\hline & & Combine & $37 / 60$ & 61.6 \\
\hline \multirow[t]{6}{*}{48} & & Control & $0 / 60$ & 0 \\
\hline & & $\mathrm{KCL}$ & $4 / 60$ & 6.6 \\
\hline & & B.t & $8 / 60$ & 13.3 \\
\hline & & B. glabra & $0 / 60$ & 0 \\
\hline & & Tet+DDVP & $10 / 60$ & 16.6 \\
\hline & & Combine & $22 / 60$ & 36.6 \\
\hline \multirow[t]{6}{*}{72} & & Control & $0 / 60$ & 0 \\
\hline & & $\mathrm{KCL}$ & $1 / 60$ & 1.6 \\
\hline & & B.t & $0 / 60$ & 0 \\
\hline & & B. glabra & $0 / 60$ & 0 \\
\hline & & Tet+DDVP & $7 / 60$ & 11.6 \\
\hline & & Combine & $8 / 60$ & 13.3 \\
\hline
\end{tabular}


Table 8. Continued.

\begin{tabular}{|c|c|c|c|c|}
\hline \multirow[t]{6}{*}{24} & Third concentration & Control & $0 / 60$ & 0 \\
\hline & & KCL (2.5 g) & $15 / 60$ & 25 \\
\hline & & B.t $(2.0 \mathrm{~g})$ & $14 / 60$ & 23.3 \\
\hline & & B. glabra $(2.5 \mathrm{~g})$ & $0 / 60$ & 0 \\
\hline & & Tet+DDVP $(0.25 \%)$ & $16 / 60$ & 26.6 \\
\hline & & Combine & $45 / 60$ & 75 \\
\hline \multirow[t]{6}{*}{48} & & Control & $0 / 60$ & 0 \\
\hline & & $\mathrm{KCL}$ & $5 / 60$ & 8.3 \\
\hline & & B.t & $9 / 60$ & 15 \\
\hline & & B. glabra & $0 / 60$ & 0 \\
\hline & & Tet+DDVP & $11 / 60$ & 18.3 \\
\hline & & Combine & $25 / 60$ & 41.6 \\
\hline \multirow[t]{6}{*}{72} & & Control & $0 / 60$ & 0 \\
\hline & & $\mathrm{KCL}$ & $3 / 60$ & 5 \\
\hline & & B.t & $7 / 60$ & 11.6 \\
\hline & & B. glabra & $0 / 60$ & 0 \\
\hline & & Tet+DDVP & $8 / 60$ & 13.3 \\
\hline & & Combine & $18 / 60$ & 30 \\
\hline
\end{tabular}

Table 9. Bioassay results of Shaf I B. thuringiensis at different concentrations showing percent mortality.

\begin{tabular}{|c|c|c|c|c|c|c|c|}
\hline \multirow{2}{*}{$\begin{array}{c}\text { Serial } \\
\text { number }\end{array}$} & \multirow{2}{*}{$\begin{array}{l}\text { Concentration } \\
(\mathrm{g})\end{array}$} & \multirow{2}{*}{$\begin{array}{l}\text { Number of used } \\
\text { larvae }\end{array}$} & \multicolumn{3}{|c|}{ Time (h) } & \multirow{2}{*}{$\begin{array}{l}\text { Percentage } \\
\text { mortality (\%) }\end{array}$} & \multirow{2}{*}{$\mathbf{R}^{2}$ of all 3 concentration } \\
\hline & & & 24 & 48 & 72 & & \\
\hline 1 & 1.0 & 60 & 11 & 8 & 5 & 40 & \multirow{4}{*}{0.9} \\
\hline 2 & 1.5 & 60 & 12 & 9 & 6 & 45 & \\
\hline 3 & 2.0 & 60 & 14 & 10 & 7 & 51.6 & \\
\hline 4 & Control & 60 & 0 & 0 & 0 & 0 & \\
\hline
\end{tabular}

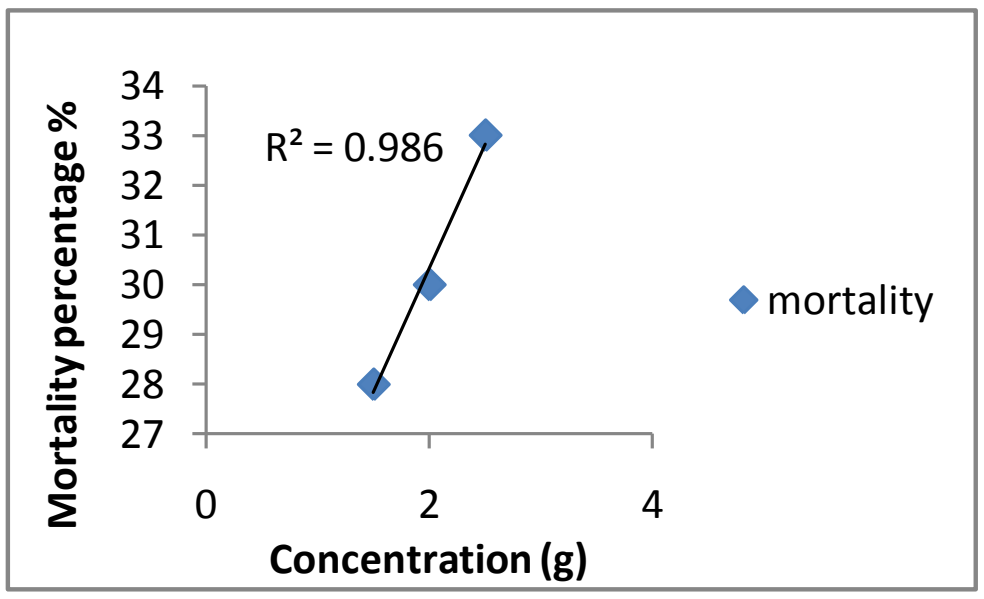

Figure 13. Regression lines of total mortality percentage versus 3 concentration of Potassium Chloride against third instar larvae of Tribolium castaneum. 


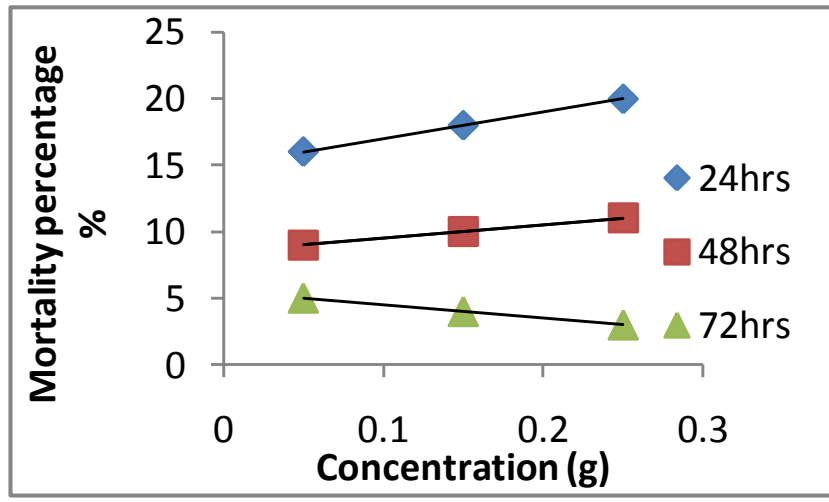

Figure 14. Regression lines of mortality percentage versus different concentration of Tetramethrin and DDVP against third instar larvae of Tribolium castaneum at different time interval.

Table 10. Toxicity of Shaf I B. thuringiensis against Tribolium castaneum showing $\mathrm{LC}_{50}$ value.

\begin{tabular}{|c|c|c|c|c|c|c|}
\hline \multirow{2}{*}{$\begin{array}{c}\text { Serial } \\
\text { number }\end{array}$} & \multirow{2}{*}{ Time (h) } & \multicolumn{3}{|c|}{ Concentration (g) } & \multirow{2}{*}{$L C_{50}(g / g)$} & \multirow{2}{*}{$\begin{array}{c}\mathrm{LC}_{50} \text { of all } 3 \text { concentration } \\
(\mathrm{g} / \mathrm{g})\end{array}$} \\
\hline & & 1.0 & 1.5 & 2.0 & & \\
\hline 1 & 24 & 11 & 12 & 14 & 6.2 & \\
\hline 2 & 48 & 8 & 9 & 9 & 8.7 & 1.8 \\
\hline 3 & 72 & 6 & 5 & 5 & 8.2 & \\
\hline
\end{tabular}

Table 11. Bioassay results of potassium chloride at different concentrations showing percent mortality.

\begin{tabular}{cccccccc}
\hline \multirow{2}{*}{$\begin{array}{c}\text { Serial } \\
\text { number }\end{array}$} & $\begin{array}{c}\text { Concentration } \\
(\mathbf{g})\end{array}$ & $\begin{array}{c}\text { Number of } \\
\text { used larvae }\end{array}$ & \multicolumn{2}{c}{ Time $(\mathbf{h})$} & & $\begin{array}{c}\text { Percentage } \\
\text { mortality (\%) }\end{array}$ & \multirow{2}{*}{$\mathbf{R}^{2}$ of all 3 concentration } \\
\hline 1 & 1.5 & 60 & 13 & 8 & 6 & 45 & \\
2 & 2.0 & 60 & 14 & 9 & 7 & 50 & \multirow{2}{*}{0.9} \\
3 & 2.5 & 60 & 15 & 10 & 8 & 55 & \\
4 & Control & 60 & 0 & 0 & 0 & 0 & \\
\hline
\end{tabular}

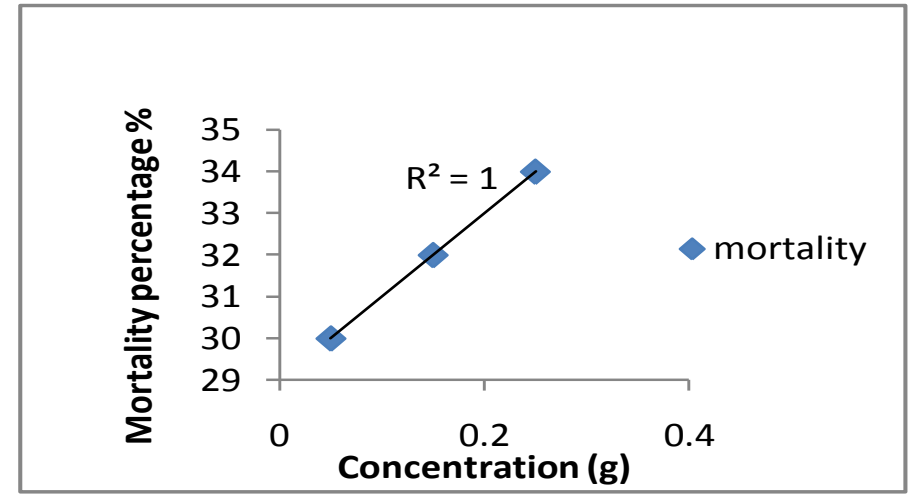

Figure 15. Regression lines of mortality percentage versus 3 concentrations of Tetramethrin and DDVP against third instar larvae of Tribolium castaneum. 


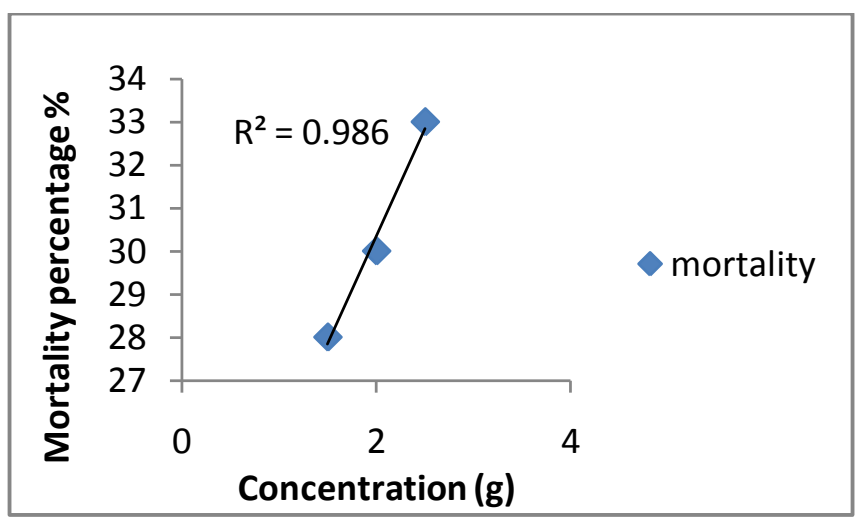

Figure 16. Regression lines of total mortality percentage versus 3 concentration of Potassium Chloride against third instar larvae of Tribolium castaneum.

Table 12. Toxicity of potassium chloride against Tribolium castaneum showing $\mathrm{LC}_{50}$ value.

\begin{tabular}{cccccccc}
\hline \multirow{2}{*}{ Serial number } & \multirow{2}{*}{ Time $(\mathbf{h})$} & \multicolumn{3}{c}{ Concentration } & $\mathbf{( g )}$ & \multirow{2}{*}{$\mathbf{L C}_{50}(\mathbf{g} / \mathbf{g})$} & \multirow{2}{*}{ LC $_{50}$ of all three concentration $(\mathbf{g} / \mathbf{g})$} \\
\cline { 3 - 5 } & 24 & 13 & $\mathbf{2 . 0}$ & $\mathbf{2 . 5}$ & 15 & 8.7 & \\
2 & 48 & 8 & 9 & 10 & 9.2 & 1.3 \\
3 & 72 & 6 & 7 & 8 & 9.0 & \\
\hline
\end{tabular}

Table 13. Bioassay results of Tetramethrin+DDVP at different concentrations showing percent mortality.

\begin{tabular}{cccccccc}
\hline Serial number & $\begin{array}{c}\text { Concentration } \\
\text { (g) }\end{array}$ & $\begin{array}{c}\text { Number of } \\
\text { used larva }\end{array}$ & \multicolumn{3}{c}{ Time $(\mathbf{h})$} & Percentage & \multirow{2}{*}{$\mathbf{R}^{2}$ of all 3concentration } \\
\cline { 5 - 6 } & $\mathbf{2 4}$ & $\mathbf{4 8}$ & $\mathbf{7 2}$ & & mortality (\%) & \\
2 & 0.05 & 60 & 16 & 9 & 5 & 50 & \\
3 & 0.15 & 60 & 18 & 6 & 4 & 56.6 & 1 \\
4 & 0.25 & 60 & 20 & 11 & 7 & 63.3 & \\
\hline
\end{tabular}

died, while according to hours, less number of insects died; at first day high number of insects become dead as $B t$ was highly effective in the beginning, and is human safe, but on the $2^{\text {nd }}$ and $3^{\text {rd }}$ day, its efficacy becomes lower and it started degrading and so there were less number of insects. Larvae showed remarkable results. Bioassay of potassium chloride of both adults and larvae showed comparably different results in case of mortality percentage and $\mathrm{LC}_{50}$. Third instar larvae were more susceptible to chemical and thus they showed greater percentage of mortality as compared to adult. Regression was equal or near to 1 . The adult showed $3.3 \mathrm{~g} / \mathrm{g}$ value of $\mathrm{LC}_{50}$ of all the three concentrations, while larvae showed $1.3 \mathrm{~g} / \mathrm{g}$ value of $\mathrm{LC}_{50}$. In the case of adult, potassium chloride caused mortality over a longer period of time, but in the case of larvae, mortality occurred within three days. $\mathrm{LC}_{50}$ value of larvae was lower as compared to adult, which indicates that potassium chloride was toxic to larvae as compared to adult.

Bioassay of $B$. glabra for both adults and larvae showed similar results, no mortality was observed and insect were repelled by $B$. glabra leaves. B. glabra prolonged the developmental period of $T$. castaneum. Bioassay of Tetramethrin and DDVP showed strong efficacy against $T$. castaneum adults and larvae. Estimated value of $\mathrm{LC}_{50}$ of adult was $0.2 \%$ while larvae showed $0.1 \%$ LC50 value. When two insecticides work together in synergism, their tendency to kill insect become higher. Tetramethrin do not show residual effect but DDVP shows residual effect which may lasts for 3 to 


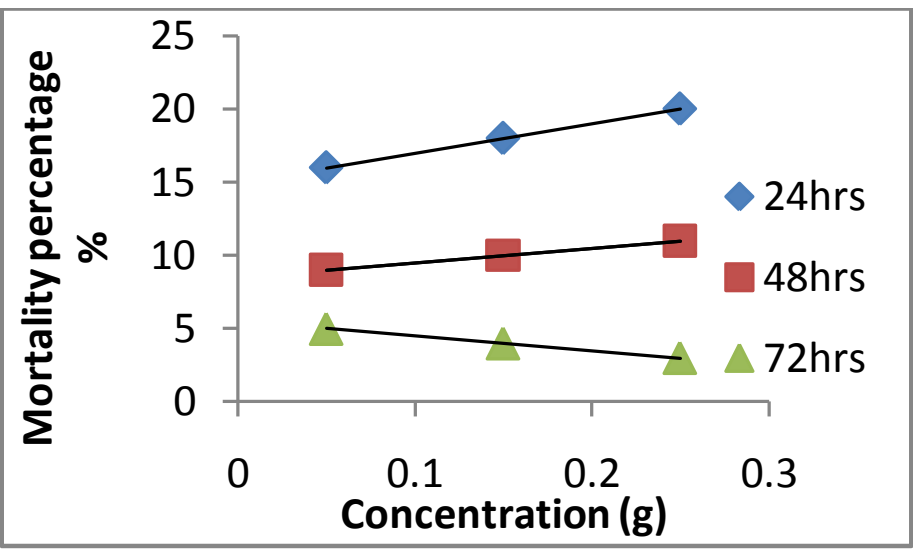

Figure 17. Regression lines of mortality percentage versus different concentration of Tetramethrin and DDVP against third instar larvae of Tribolium castaneum at different time interval.

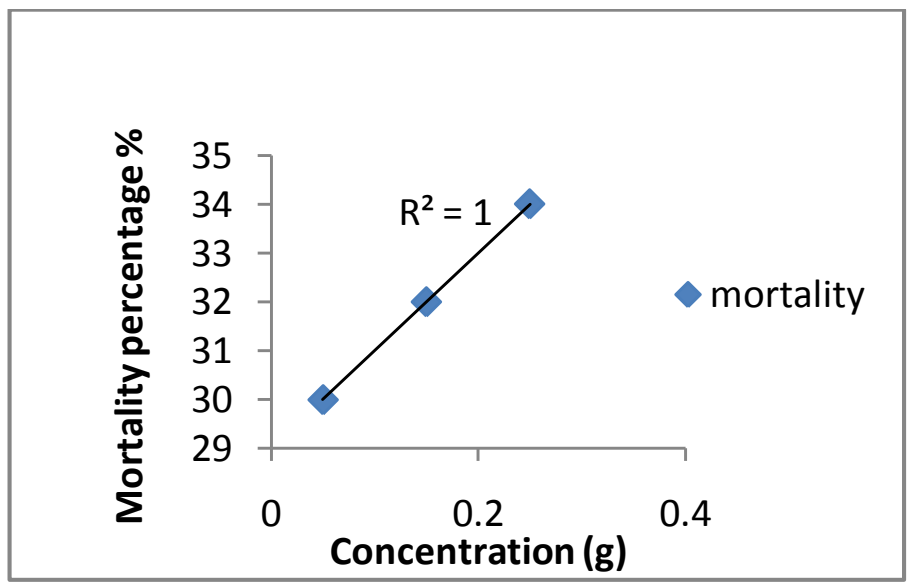

Figure 18. Regression lines of mortality percentage versus 3 concentrations of Tetramethrin and DDVP against third instar larvae of Tribolium castaneum.

Table 14. Toxicity of Tetramethrin+DDVP against Tribolium castaneum showing LC $_{50}$ value.

\begin{tabular}{|c|c|c|c|c|c|c|}
\hline \multirow{2}{*}{$\begin{array}{c}\text { Serial } \\
\text { number }\end{array}$} & \multirow{2}{*}{ Time (h) } & \multicolumn{3}{|c|}{ Concentration (g) } & \multirow{2}{*}{ LC $_{50}(\%)$} & \multirow{2}{*}{$\mathrm{LC}_{50}$ of all 3 concentration } \\
\hline & & 0.05 & 0.15 & 0.25 & & \\
\hline 1 & 24 & 16 & 18 & 20 & 0.6 & \multirow{3}{*}{1.9} \\
\hline 2 & 48 & 9 & 10 & 11 & 1.6 & \\
\hline 3 & 72 & 5 & 6 & 7 & 1.5 & \\
\hline
\end{tabular}

4 days. Both insecticides either used in low concentration or high concentration, killed adult and larvae of $T$. castaneum within 3-4 days or were effective for stored grain pests. As the concentration increased, more number of insects died, but rate of mortality became low day after day. They are very useful for integrated pest management strategies.

In the combine bioassay, all the elements were mixed 
Malik et al. $\quad 7415$

Table 15. Comparison of Individual and Combine effect of Shaf I Bacillus thuringiensis, Potassium chloride, Bougainvillea glabra and Tetramethrin+DDVP on Tribolium castaneum larvae.

\begin{tabular}{|c|c|c|c|c|}
\hline Time Interval (h) & Concentration & $\begin{array}{l}\text { Combine and Individual } \\
\text { Concentration mixed with diet }\end{array}$ & $\begin{array}{c}\text { Observed } \\
\text { mortality (D/T) }\end{array}$ & $\begin{array}{l}\text { Percentage } \\
\text { mortality (\%) }\end{array}$ \\
\hline \multirow[t]{6}{*}{24} & First concentration & Control & $0 / 60$ & 0 \\
\hline & & $\mathrm{KCL}(1.5 \mathrm{~g})$ & $13 / 60$ & 21.6 \\
\hline & & B.t $(1.0 \mathrm{~g})$ & $11 / 60$ & 18.3 \\
\hline & & B. glabra $(1.5 \mathrm{~g})$ & $0 / 60$ & 0 \\
\hline & & Tet+DDVP $(0.05 \%)$ & $16 / 60$ & 26.6 \\
\hline & & Combine & $40 / 60$ & 66.6 \\
\hline \multirow[t]{6}{*}{48} & & Control & $0 / 60$ & 0 \\
\hline & & $\mathrm{KCL}$ & $8 / 60$ & 13.3 \\
\hline & & B.t & $8 / 60$ & 13.3 \\
\hline & & B. glabra & $0 / 60$ & 0 \\
\hline & & Tet+DDVP & $9 / 60$ & 15 \\
\hline & & Combine & $25 / 60$ & 41.6 \\
\hline \multirow[t]{6}{*}{72} & & Control & $0 / 60$ & 0 \\
\hline & & $\mathrm{KCL}$ & $6 / 60$ & 10 \\
\hline & & B.t & $5 / 60$ & 8.3 \\
\hline & & B. glabra & $0 / 60$ & 0 \\
\hline & & Tet+DDVP & $5 / 60$ & 8.3 \\
\hline & & Combine & $16 / 60$ & 26.6 \\
\hline \multirow[t]{6}{*}{24} & Second concentration & Control & $0 / 60$ & 0 \\
\hline & & $\mathrm{KCL}(2.0 \mathrm{~g})$ & $14 / 60$ & 23.3 \\
\hline & & B.t $(1.5 \mathrm{~g})$ & $12 / 60$ & 20 \\
\hline & & B. glabra $(2.0 \mathrm{~g})$ & $0 / 60$ & 0 \\
\hline & & Tet+DDVP $(0.15 \%)$ & $18 / 60$ & 30 \\
\hline & & Combine & $44 / 60$ & 73.3 \\
\hline \multirow[t]{6}{*}{48} & & Control & $0 / 60$ & 0 \\
\hline & & $\mathrm{KCL}$ & $9 / 60$ & 15 \\
\hline & & B.t & $9 / 60$ & 15 \\
\hline & & B. glabra & $0 / 60$ & 0 \\
\hline & & Tet+DDVP & $10 / 60$ & 16.6 \\
\hline & & Combine & $28 / 60$ & 46.6 \\
\hline \multirow[t]{6}{*}{72} & & Control & $0 / 60$ & 0 \\
\hline & & $\mathrm{KCL}$ & $7 / 60$ & 11.6 \\
\hline & & B.t & $6 / 60$ & 10 \\
\hline & & B. glabra & $0 / 60$ & 0 \\
\hline & & Tet+DDVP & $6 / 60$ & 10 \\
\hline & & Combine & $19 / 60$ & 31.6 \\
\hline \multirow[t]{7}{*}{24} & Third concentration & Control & & \\
\hline & & $\mathrm{KCL}(2.5 \mathrm{~g})$ & $0 / 60$ & 0 \\
\hline & & B.t $(2.0 \mathrm{~g})$ & $15 / 60$ & 25 \\
\hline & & B. glabra $(2.5 \mathrm{~g})$ & $14 / 60$ & 23.3 \\
\hline & & Tet+DDVP $(0.25 \%)$ & $0 / 60$ & 0 \\
\hline & & Combine & $20 / 60$ & 33.3 \\
\hline & & Control & $49 / 60$ & 81.6 \\
\hline \multirow[t]{2}{*}{48} & & $\mathrm{KCL}$ & $0 / 60$ & 0 \\
\hline & & B.t & $10 / 60$ & 16.6 \\
\hline
\end{tabular}


Table 15. Continued.

\begin{tabular}{|c|c|c|c|}
\hline & B. glabra & $10 / 60$ & 16.6 \\
\hline & Tet+DDVP & $0 / 60$ & 0 \\
\hline & Combine & $11 / 60$ & 18.3 \\
\hline \multirow[t]{6}{*}{72} & Control & $31 / 60$ & 51.6 \\
\hline & KCL & $0 / 60$ & 0 \\
\hline & B.t & $8 / 60$ & 13.3 \\
\hline & B. glabra & $7 / 60$ & 11.6 \\
\hline & Tet+DDVP & $0 / 60$ & 0 \\
\hline & Combine & $7 / 60$ & 11.6 \\
\hline
\end{tabular}

together at three different concentrations; in the case of adult percentage, mortality was low at first and second combination but high at third combination. While in the case of larvae, all three combinations showed significant results and high mortality rate was revealed. This is a new study in which combining together all the essential elements are very effective against T.castaneum. All elements are safe for humans and animals. Their synergistic effect cannot only control stored target pest but also non-target organisms. The present result can trace new strategies for international pest management programs.

The crystal proteins of B.t had insecticidal properties against different pests. One crystal protein may be effective for many different kinds of pests. Likewise boric acid is a chemical and cypermethrin an insecticide which have no residual effects and safe for humans and other mammals as well as for the whole environment. In godowns the spray of insecticide kept the grain products safe from the different stored product pests. Different kinds of formulations were made from these biopesticides which helped in for the control of not only stored product pests but for the control of other forest, agriculture and household pests.

\section{REFERENCES}

Alabi T, Michaud JP, Arnaud L, Haubruge E (2008). A comparative study of cannibalism and predation in seven species of flour beetle. Ecol. Entomol. 33:716-716.

Alanko K, Tuomi T, Vanhanen M, Pajari-Backas M, Kanerva L, Havu K, Saarinen K, Bruynzeel DP (2000). Occupational IgE-mediated allergy to Tribolium confusum (confused flour beetle). Allergy 55:879-882.
Bucher G, Scholten J, Klingler M (2005). Parental RNAi in Tribolium (Coleoptera). J. Curr. Biol. 12:85-86.

Garcia R,Ninfa M (2009). Biopesticide production from Bacillus thuringiensis: An environmentally friendly alternative. J. Biotechnol. 3(1):28-36.

Haq T, Usmani NF, Abbas T (2005). Screening of plant leaves as grain protectants against Tribolium castaneum during storage. Pak. J. Bot. 37(1):149-153.

Khan KI (2006). Enhancement of virulence of Bacillus thuringiensis and Serratia marcescens by chemicals. J. Res. Sci. 17(1):34-43.

Lloyd JC (2003). The toxicity of pyrethrins and five synthetic pyrethroids, to Tribolium castaneum (Herbst), and susceptible and pyrethrin-resistant Sitophilus granarius (L.). J. Stor. Prod. Res. 9(2):77-79.

Rahman MA, Haque AHMM, Ahmed F, Hossain ATM, Hussain MF (2007). Efficacy of commonly used insecticides on the Red flour Beetle. Int. J. Sustain. Crop. Prod. 2(5):08-11.

Scott JG, Snodgrass MC (2000). Is Apis mellifera more sensitive to insecticides than other insects? J. Pest. Manag. Sci. 66:1171-1180.

Tripathi AK, Prajapati V, Aggarwal KK, Kumar S (2001). Toxicity, feeding deterrence, and effect of activity of 1,8,-Cineole from Artemisia annua on progeny production of Tribolium castaneum (Coleoptera: Tenebrionidae). J. Econ. Entomol. 94:979-983.

Via S (1999). Cannibalism facilitates the use of a novel environment in the flour beetle, Tribolium castaneum. Heredity 82:267-275.

Weston PA, Rattlingourd PL (2000). Progeny production by Tribolium castaneum (Coleoptera: Tenebrionidae) and Oryzaephilus surinamensis (Coleoptera: Silvanidae) on maize previously infested by Sitotroga cerealla (Lepidoptera: Gelechiidae). J. Econ. Entomol. 93:533-536. 